\title{
Multipotent stem cells isolated from the adult mouse retina are capable of producing functional photoreceptor cells
}

\author{
Tianqing $\mathrm{Li}^{1, *}$, Michelle Lewallen ${ }^{1, *}$, Shuyi Chen ${ }^{1, *}$, Wei $\mathrm{Yu}^{1}$, Nian Zhang ${ }^{1}$, Ting Xie ${ }^{1,2}$ \\ ${ }^{I}$ Stowers Institute for Medical Research, 1000 East 50th Street, Kansas City, MO 64110, USA; ${ }^{2}$ Department of Anatomy and Cell \\ Biology, University of Kansas School of Medicine, 3901 Rainbow Blvd, Kansas City, KS 66160, USA
}

Various stem cell types have been tested for their potential application in treating photoreceptor degenerative diseases, such as retinitis pigmentosa (RP) and age-related macular degeneration (AMD). Only embryonic stem cells (ESCs) have so far been shown to generate functional photoreceptor cells restoring light response of photoreceptordeficient mice, but there is still some concern of tumor formation. In this study, we have successfully cultured Nestin $^{+} \mathrm{Sox}^{+}{ }^{+} \mathrm{Pax6}^{+}$multipotent retinal stem cells (RSCs) from the adult mouse retina, which are capable of producing functional photoreceptor cells that restore the light response of photoreceptor-deficient $r d 1$ mutant mice following transplantation. After they have been expanded for over 35 passages in the presence of FGF and EGF, the cultured RSCs still maintain stable proliferation and differentiation potential. Under proper differentiation conditions, they can differentiate into all the major retinal cell types found in the adult retina. More importantly, they can efficiently differentiate into photoreceptor cells under optimized differentiation conditions. Following transplantation into the subretinal space of slowly degenerating $r d 7$ mutant eyes, RSC-derived photoreceptor cells integrate into the retina, morphologically resembling endogenous photoreceptors and forming synapases with resident retinal neurons. When transplanted into eyes of photoreceptor-deficient $r d 1$ mutant mice, a RP model, RSC-derived photoreceptors can partially restore light response, indicating that those RSC-derived photoreceptors are functional. Finally, there is no evidence for tumor formation in the photoreceptor-transplanted eyes. Therefore, this study has demonstrated that RSCs isolated from the adult retina have the potential of producing functional photoreceptor cells that can potentially restore lost vision caused by loss of photoreceptor cells in RP and AMD.

Keywords: retinal stem cells; photoreceptor cells

Cell Research (2013) 23:788-802. doi:10.1038/cr.2013.48; published online 9 April 2013

\section{Introduction}

Dysfunction and death of retinal neurons are among the most common health problems for aged people. Each day, millions of people live in darkness caused by retinal degenerative diseases, such as glaucoma, retinitis pigmentosa (RP), and age-related macular degeneration (AMD). Current therapies for these diseases are largely preventative and treatments capable of curing these diseases by restoring lost visual function remain to be developed. With the aging population rapidly growing, the

\footnotetext{
*These three authors contributed equally to this work.

Correspondence: Ting Xie

E-mail: tgx@stowers.org

Received 5 December 2012; revised 17 January 2013; accepted 28 February 2013; published online 9 April 2013
}

need to develop effective methods to recover vision for retinal degeneration disease patients is more urgent than ever. Among methods currently undergoing development, stem cell-based cell replacement therapy represents one of the most promising. In 2006, Maclaren et al. [1] showed that immature post-mitotic photoreceptor precursors, when transplanted into the subretinal space, could integrate into the outer photoreceptor cell layer, differentiate into rod photoreceptors, and establish synaptic connections with interneurons in the inner nuclear layer. Later, the same group further showed that the transplanted cells are able to form visual circuitry all the way to the visual cortex and restore vision of rod photoreceptorimpaired mice [2]. These transplantation experiments proved the principle that cell transplantation therapy is an effective method for treating blindness. Now, the biggest challenge facing the medical community for the use 
of cell-replacement therapy to treat retinal degenerative diseases is to find appropriate cellular sources for transplantation.

Photoreceptor precursors isolated from the developing retina have given the best vision recovery results [2], however, the source for such cells is extremely limited and their clinical use raises ethical concerns. Embryonic stem cells (ES cells) and induced pluripotent stem (iPS) cells represent two of the most attractive subjects in regenerative medicine research, due to their unlimited proliferation ability and tremendous differentiation potential. It has been shown that ES cells can be induced to differentiate to retinal progenitor cells $[3,4]$, rod and cone photoreceptor cells, retinal pigmented epithelial (RPE) cells [5], and can even generate a three-dimensional optic cup $[6,7]$ in culture dishes. These exciting results have inspired several groups of researchers to test the idea of using ES cell- or iPS cell-derived retinal cells to treat diseases of retinal degeneration. So far, the results are promising: ES/iPS cell-derived retinal cells are able to integrate into retina tissues, express markers for retinal neurons, and even rescue the light response of photoreceptor-impaired animals [8-10]. While the use of iPS cells circumvents the ethical drawbacks that accompany the use of ES cells, the oncogenic properties of both ES and iPS cells are currently an unavoidable safety issue when using them for clinical therapy. Indeed, transplantation experiments using ES cell-derived retinal cells have shown teratoma formation in transplanted eyes due to contamination of undifferentiated ES cells $[10,11]$.

When compared with ES cells, tissue-specific adult stem cells are more efficient at generating the cells of the tissues from which they originate. This combined with the reduced concern for tumor formation makes them another attractive renewable cellular source for cell replacement therapy. Hence, the presence and location of stem cells in the adult retina is under intense investigation. In 2000, Tropepe et al. [12] reported isolation of adult retinal stem cells from pigmented ciliary body epithelium, which could form neurospheres and could differentiate into retina-specific cell types, including rod photoreceptors. Following this report, different groups have isolated similar cell populations from rat, pig, and human ciliary body [13-15]. Recently, the retinal stem cell properties of ciliary body-derived cells have been challenged by several reports, and their usage for retinal cell replacement therapy is being scrutinized $[16,17]$. In the adult brain, it has long been known that a subpopulation of glia-like cells in the subventricular zone of the lateral ventricle and the dentate gyrus of the hippocampus function as neural stem cells [18]. In zebrafish, it has been demonstrated that Müller cells, the glial cells in neural retina, function as retinal stem cells to regenerate retinal neurons after injury $[19,20]$. In mammals, under severe injury, Müller cells undergo reactive gliosis, and may reenter the cell cycle. However, unlike Müller cells in lower vertebrates, the stimulated Müller cells in mammals only exhibited very limited regeneration capacity [21-23]. Various efforts have also been made to isolate cells with stem cell-like properties from embryonic and adult retinas [24-28], however, none of these cell populations have been shown to be able to provide functional rescue of vision in animal models of retinal degeneration. In this study, we isolated a population of multipotent retinal stem cells (RSCs) from the adult mouse retina that could be propagated for over 35 passages, and that give rise to all the major cell types in the neural retina in vitro. When transplanted into the subretinal space of the murine eye, these RSCs integrate into the host retina and differentiate to photoreceptor cells that form synapses with resident retinal interneurons. More importantly, transplanted cells partially restored the light response of photoreceptor-deficient mice, demonstrating therapeutic potential of these RSCs.

\section{Results}

Retinal cells with stem cell characteristics isolated from the adult neuroretina

To test whether retinal stem cells can be cultured from adult retina, adult eyes were dissected and single-cell suspensions from neuroretina were plated on gelatincoated plates (Figure 1A). Within the first few days of culture in RCM supplemented with EGF and bFGF, most cells died while only a few cells attached to the plates. After 2-3 weeks, the cells grew in clusters of heterogeneous morphology and formed confluent colonies. Most of these cells lost their proliferative ability over passaging. After 3-4 weeks of primary culture, very few spindle-shaped cells of smaller size could be found in the primary culture (Figure 1B). These cells formed colonies morphologically distinct from other cells and exhibited stable proliferation with homogenous morphology. By using Accutase, a more gentle enzyme than trypsin, and carefully controlling digestion time, the stem-like cells were able to be selectively freed from the plate while leaving the other cell types undisturbed and still attached to the plate. These cells can be cultured in vitro for at least 5 months (over passage 35), passaging every 3-5 days (Figure 1C). Of the $30 \mathrm{CD}-1$ and B6 retina samples processed and cultured by two independent investigators, 9 total cell lines were isolated.

Immunostaining of long-term cultured retinal stem cells showed that these cells expressed high levels of 
A
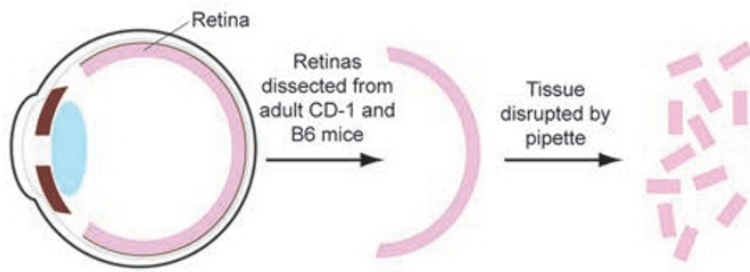

Enzymatic

digestion

to produce

$\stackrel{\text { single cells }}{\longrightarrow}$

Cells seeded

coated

plates
Media change every 2 days

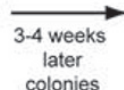

colonies emerge
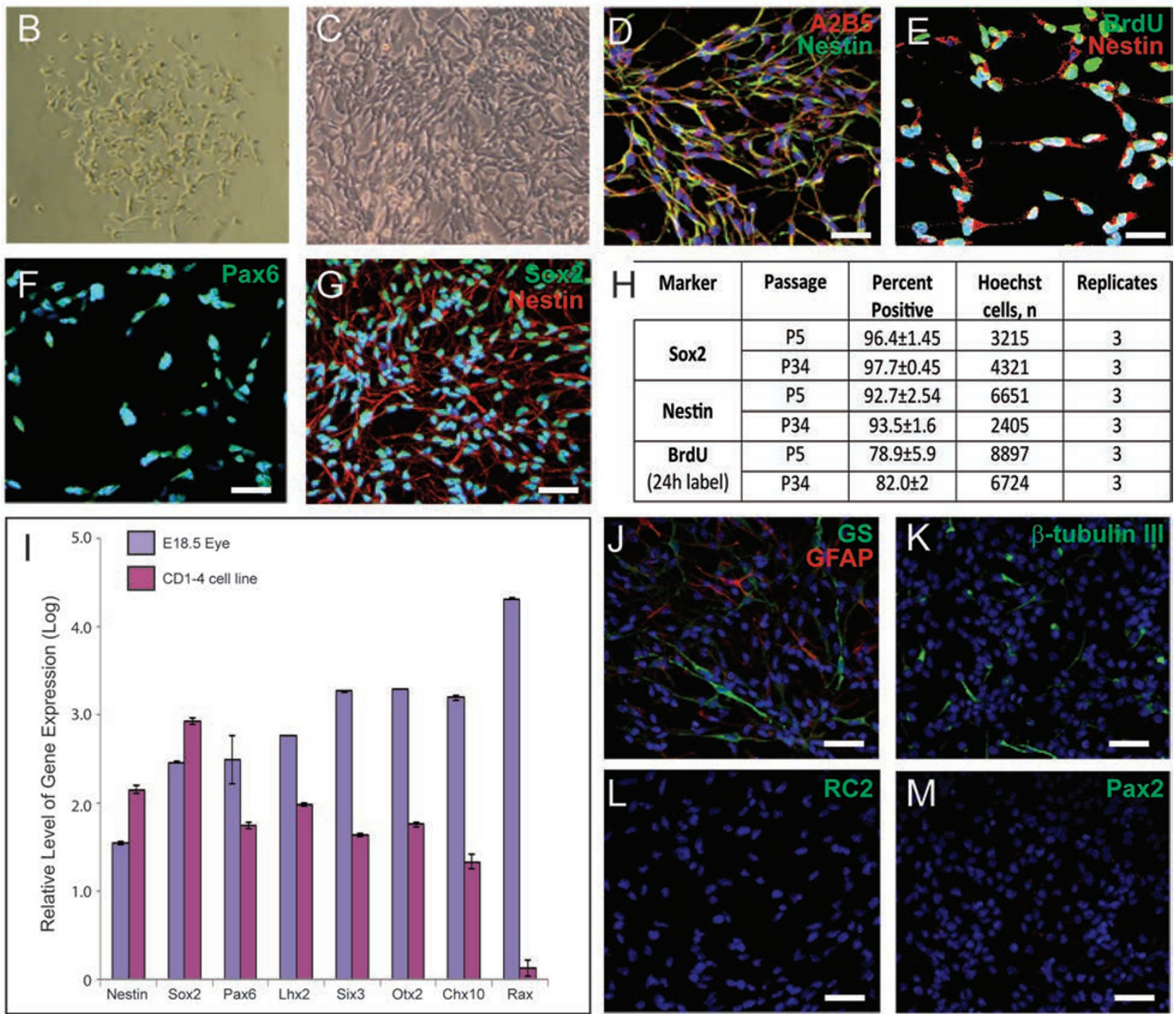

Figure 1 Retinal stem cells were isolated from adult retina. (A) Schematic representation of retinal stem cell isolation procedure. (B) Phase contrast imaging of a representative retinal stem cell colony. After 3-4 weeks of primary culture, very few spindle-shaped cells with smaller size could be found in the primary culture. (C) Phase contrast imaging of retinal stem cells cultured for 24 passages. (D-G) Retinal stem cells express high levels of retinal stem cell markers A2B5 (red) and Nestin (green) (D); Nestin (red) and BrdU (green) (E); Pax6 (F); Nestin (red) and Sox2 (green) (G). (H) Quantification of Sox2- and Nestin-positive immunostaining and BrdU incorporation at passages 5 and 34. (I) Retinal stem cells express mRNA transcripts of neural and retinal stem cell markers Nestin, Sox2, and Pax6, Lhx2, Six3, Otx2 and Chx10, and low levels of Rax. Gene expression levels were determined by quantitative RT-PCR analysis and values are presented as the log of the mean fold-increase over the expression observed in adult mouse fibroblasts (three replicates, \pm SEM). Gene expression levels in embryonic E18.5 eye are provided as a comparison. Retinal stem cells express low levels of GS (green) and GFAP (red) (J), few express low levels of $\beta$-tubulin III (K), and all are negative for RC2 (L) and Pax2 (M). Scale bars, $50 \mu \mathrm{m}$ (D, G-M) and 25 $\mu \mathrm{m}(\mathbf{E}, \mathbf{F})$. Blue, DAPI. 
Nestin, Sox2 [29], Pax6 [30], and A2B5 [31] (Figure 1D$1 \mathrm{G})$. Expression was confirmed at various passages up to the 34th passage with no observed decrease in expression (Figure 1H). Additionally, quantitative RT-PCR analysis of one representative cell line confirmed expression of Nestin, Sox 2 and Pax6, and demonstrated high expression levels of eye field factors, including Lhx2, Six3, Otx2, and Chx10 [32] (Figure 1I). However, Rax expression is low, possibly as a result of in vitro culturing or adult cell origin, in which Rax expression is absent, or both (Figure 1I). These cells express low levels of Müller cell markers GFAP and GS (Figure 1J). We analyzed the GS and GFAP expression of five cell lines and found that the expression levels and locations of GS and GFAP significantly varied among different cell lines (Supplementary information, Figure S1). These retinal stem cells do not express the markers of radial glial cells, RC2 [33] or Pax2 [34] (Figure 1L and 1M). BrdU incorporation for $24 \mathrm{~h}$ into cells at passage 5 and passage 34 demonstrated that the cells maintained high and stable proliferation abilities in long-term culture (Figure 1E and $1 \mathrm{H}$ ).

Occasionally, some cells were observed that express $\beta$-tubulin III (early neuronal marker) and high levels of GS and GFAP (Müller cell markers), with long cellular processes (Figure 1J and 1K). By immunostaining, we determined that the expression of Nestin and these markers did not overlap well: the cells with high levels of expression of GS, GFAP and $\beta$-tubulin III expressed low levels of Nestin (Supplementary information, Figure S2A-S2C). Conversely, the cells with high levels of Nestin expressed no or low levels of GFAP, GS and $\beta$-tubulin III (Supplementary information, Figure S2A$\mathrm{S} 2 \mathrm{C})$. Double staining further showed that GFAP ${ }^{\text {high }}$ cells are also $\mathrm{GS}^{\text {high }}$, and $24 \mathrm{~h} \mathrm{BrdU}$ incorporation showed that $95 \%$ of GFAP ${ }^{\text {high }}$ cells and most of $\beta$-tubulin III-positive cells have no or low BrdU incorporation (Supplementary information, Figure S2D-S2F). Together, these data indicated that GFAP ${ }^{\text {high }}$, GS ${ }^{\text {high }}$ and $\beta$-tubulin III-positive cells with long processes are spontaneously-differentiated cells from retinal stem cells.

\section{Differentiation of retinal stem cells to retinal cells in vi- tro}

To test the ability of retinal stem cells to differentiate into retinal cells, we designed several differentiation protocols. To test whether all cell lines have a similar potential to differentiate into retinal cells, we analyzed four of the nine cell lines. We found that different cell lines have varying differentiation potentials for each type of retinal cells. The results of the differentiation studies were compiled and summarized in Supplementary information, Table S1. CD1-4 and B6-2 could differentiate into seven types of retinal cells, and B6-5 and CD1-1 could only differentiate into a limited number of retinal cell types. We chose the CD1-4 cell line as a representative cell line for all subsequent experiments. When only bFGF was added into basic differentiation medium containing B27, CD1-4 retinal stem cells could differentiate into five types of retinal cells, including ganglion cells, Müller cells, rod photoreceptor cells, cone photoreceptor cells and bipolar cells, but not into amacrine cells and horizontal cells. By immunostaining analysis, differentiated cells expressing the following markers were observed: Vimentin, GS and GFAP (markers of Müller cells) (Figure 2A-2D); Recoverin and Rhodopsin (photoreceptor cells) (Figure 2E-2F); PKC (bipolar cells) (Figure 2G); and $\beta$-tubulin III, Isl-1, NeuN, NF-H, and MAP2 (ganglion cells) (Figure 2H-2K). Quantitative analysis of differentiated cells showed that most of the cells were ganglion cells $(33.97 \% \pm 3.29 \%$; three independent experiments) and Müller cells $(30.05 \% \pm 0.76 \%)$, and other differentiated cell types comprised $\sim 10 \%$ (Supplementary information, Table S2A). To induce the differentiation of horizontal cells, $10 \mathrm{ng} / \mathrm{ml} \mathrm{NGF}$ and $10 \mathrm{ng} / \mathrm{ml} \mathrm{IGF-1} \mathrm{were}$ added into bFGF-containing differentiation medium. On Day $8,5.43 \% \pm 0.61 \%$ (three independent experiments) of cells expressed Calbindin (Figure 2L and Supplementary information, Table S2B). In the same differentiation medium, only $2.23 \% \pm 0.32 \%$ of cells expressed amacrine cell marker Pax6 (Supplementary information, Table S2B) and no cells were positive for HPC-1. Previous studies showed that Notch signaling can cause abnormal growth and interfere with the differentiation of multiple retinal cell types [35]. Adding JAG1 peptide to differentiation media significantly promoted amacrine cell differentiation, as determined by expression of Pax6 and HPC1 (Figure 2M-2N and Supplementary information, Figure S3A-S3C). We observed that $27.5 \% \pm 4.58 \%$ (in total 1 996 cells examined in three independent experiments) of the cells were HPC-1 positive after activation of Notch signaling. Furthermore, the cells acquired mature cell morphology with long and fine processes (Supplementary information, Figure S3B). Western blotting data further confirmed the elevated expression of HPC-1 with addition of JAG1 peptide and thus amacrine cell differentiation (Supplementary information, Figure S3D).

To further induce the maturation of ganglion cells, on Day 6, $10 \mathrm{ng} / \mathrm{ml} \mathrm{BDNF}, 100 \mathrm{ng} / \mathrm{ml} \mathrm{IGF-1} \mathrm{and} 10 \mathrm{ng} / \mathrm{ml}$ GDNF were added to the basic differentiation medium. On Day 14, double immunostaining showed that $89 \%$ $\pm 1.9 \%$ of $\beta$-tubulin III $^{+}$cells expressed Isl- $1,87.5 \% \pm$ $1.35 \%$ of $\beta$-tubulin $\mathrm{III}^{+}$cells also expressed MAP2, and $90.2 \% \pm 1.6 \%$ of $\beta$-tubulin $\mathrm{III}^{+}$cells expressed NeuN (data not shown). Differentiated ganglion cells had typical 

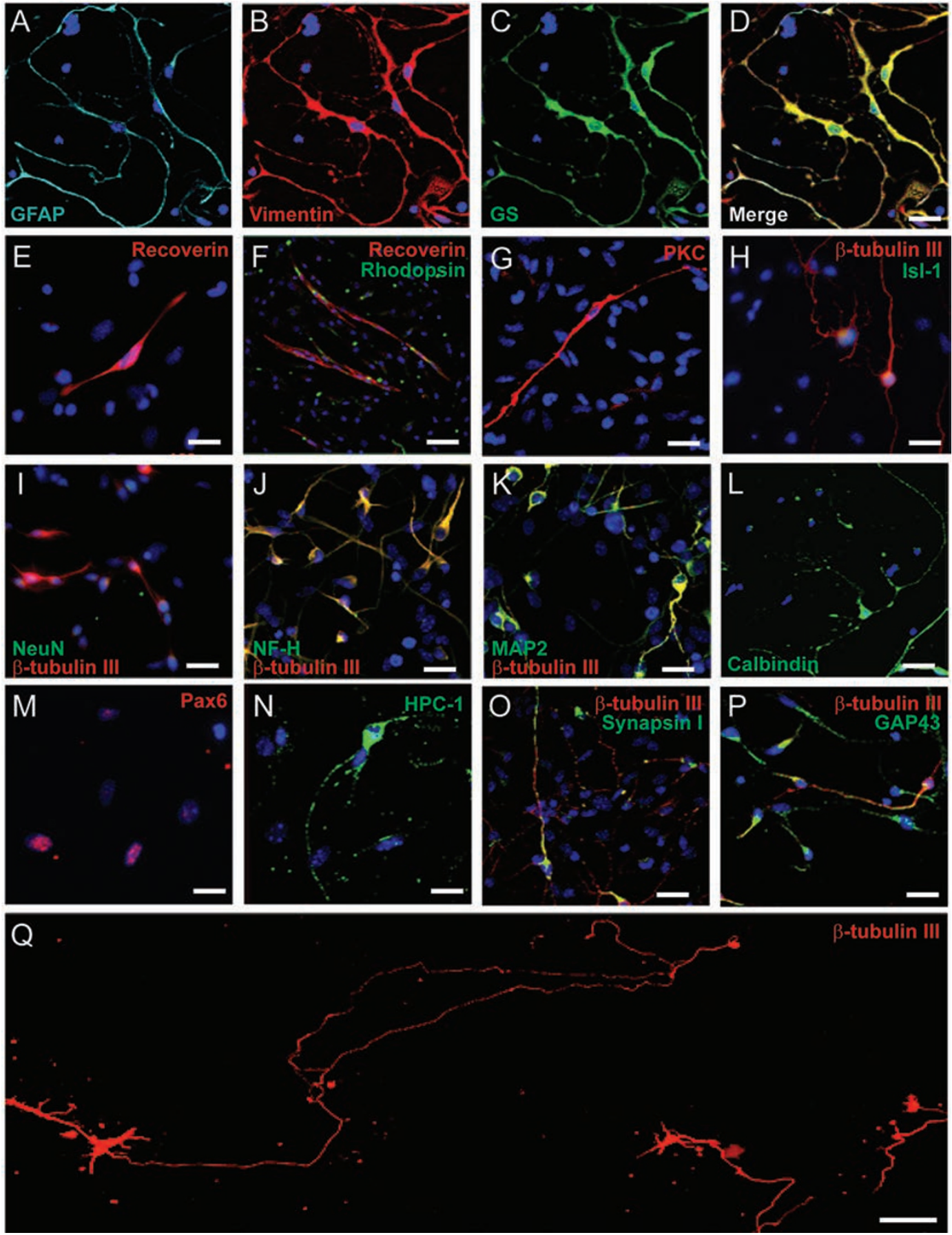

Figure 2 Generation of mature retinal cells from retinal stem cells in vitro. In bFGF+B27-containing differentiation medium, retinal stem cells can differentiate into Müller cells (A-D), coexpressing GFAP (A), Vimentin (B), and GS (C); a few photoreceptor cells can be induced from retinal stem cells, expressing Recoverin (E-F) and Rhodopsin (F); retinal stem cells are induced into bipolar cells (PKC, G) and ganglion cells (H-K). Double immunostaining shows coexpression of $\beta$-tubulin III with Isl-1(H), NeuN (I), NF-H (J), or MAP2 (K) in the differentiated retinal ganglion cells. In differentiation medium containing $10 \mathrm{ng} / \mathrm{ml} \mathrm{bFGF}, 10 \mathrm{ng} / \mathrm{ml} \mathrm{NGF}$ and $10 \mathrm{ng} / \mathrm{ml}$ IGF-1 for 8 days, a few retinal stem cells differentiate into horizontal cells with the expression of Calbindin (L). In the presence of JAG1 peptide, retinal stem cells differentiate into mature amacrine cells, expressing Pax6 (M) and HPC-1 (N). Differentiated ganglion cells express mature neuron axon markers, Synapsinl (0) and GAP43 (P). (Q) After 6 days in bFGF-containing medium and 8 days in the same medium supplemented with $10 \mathrm{ng} / \mathrm{ml}$ BDNF, $100 \mathrm{ng} / \mathrm{ml} \mathrm{IGF-1} \mathrm{and} 10 \mathrm{ng} / \mathrm{ml}$ GDNF, mature ganglion cells were observed with single very long axons, some measuring 1.5$2 \mathrm{~mm}$. Scale bars, $25 \mu \mathrm{m}$ (D, E, G-P), $50 \mu \mathrm{m}$ (F) and $100 \mu \mathrm{m}$ (Q). Blue, DAPI. 
ganglion cell morphology, with long axons expressing axon makers Synapsin I and GAP43 and many dendrites (Figure 2O-2P). Ganglion cells have one long axon targeting the brain in vivo. We found that some differentiated ganglion cells have one very long axon, even up to 1.5-2 mm (Figure 2Q).

\section{Retinal stem cells can differentiate into highly-enriched photoreceptor cells}

Previous studies showed retinoic acid (RA) and inhibition of Notch signaling (DAPT, $\gamma$-secretase inhibitor) can promote the differentiation of photoreceptor cells in organ culture, in vitro cell culture and in vivo [36]. To optimize the in vitro culture conditions for photoreceptor differentiation, we also used bFGF, taurine and docosahexaenoic acid (DHA), which are reported to have positive effects on the genesis of rods from embryonic (or neonatal) retinal progenitors in vitro [37]. The combination of these factors promoted the expression of photoreceptor progenitor marker Crx by Day 2 (Figure 3A). After continual exposure of these factors for another 4 days and then maturation for another 4 days in the presence of BDNF, IGF-1 and NGF, the differentiated photoreceptor cells express the markers of mature photoreceptor cells, Recoverin and Rhodopsin (Figure 3B-3C). Quantification of Recoverin-positive cells showed that this cell population represents $57.27 \% \pm 8.99 \%$ of the total cell population (in total 7854 cells examined in four independent
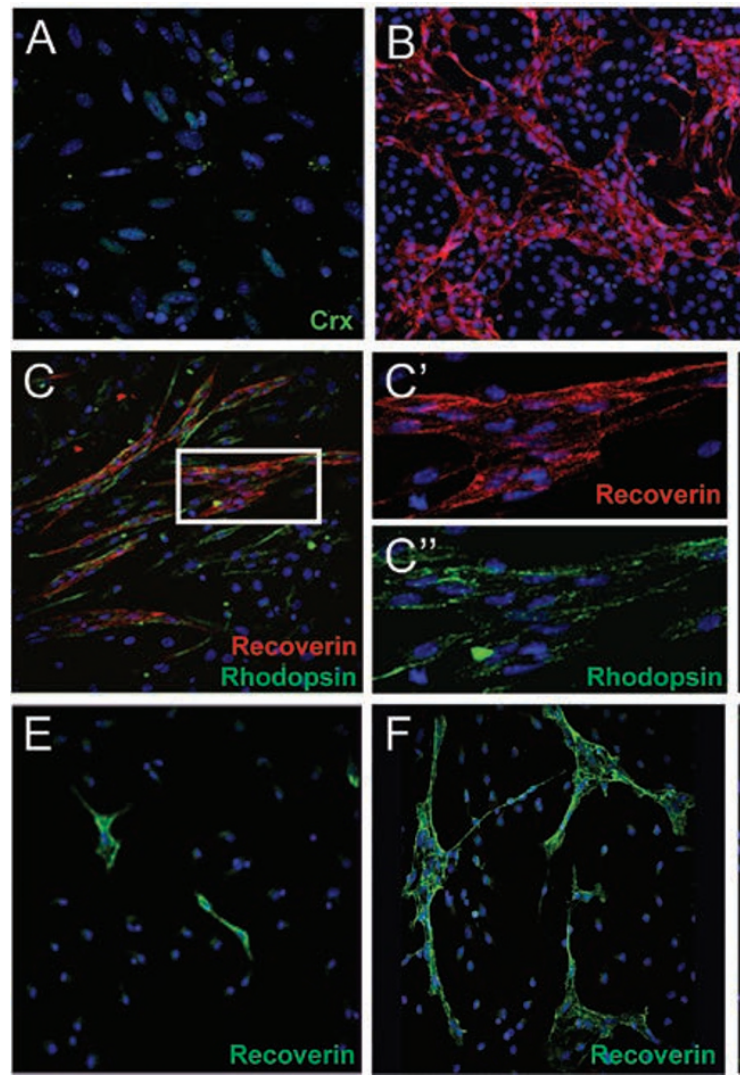
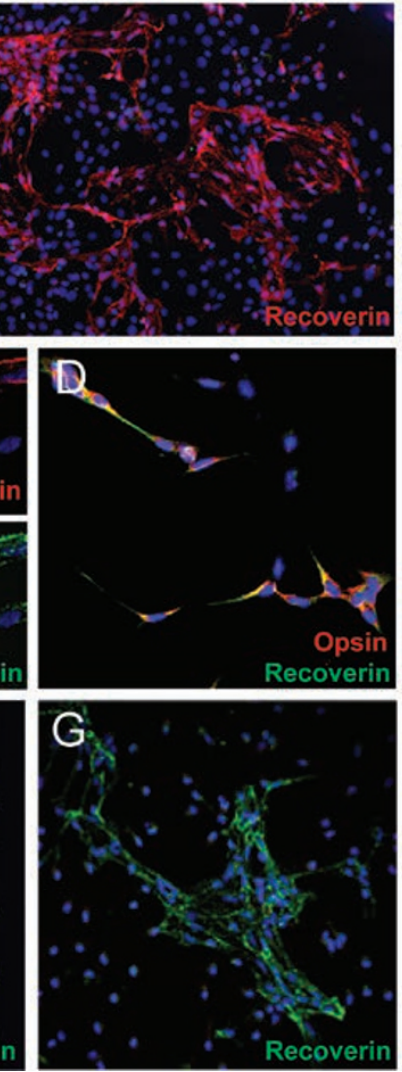
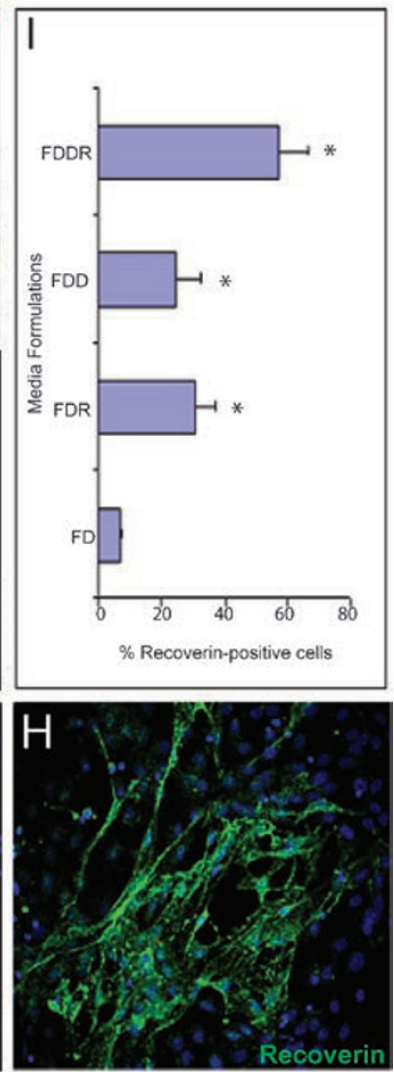

Figure 3 Retinal stem cells can differentiate into highly enriched photoreceptor cells. The combination of bFGF, docosahexaenoic acid (DHA), retinoic acid (RA), and DAPT ( $\gamma$-secretase inhibitor) promotes the expression of photoreceptor progenitor marker Crx after 2 days (green) (A). After continual exposure of these factors for another 4 days and then maturation for another 4 days in the presence of BDNF, IGF-1 and NGF, the differentiated cells express a marker of mature photoreceptors, Recoverin (red) (B). (C) Recoverin-positive differentiated photoreceptors (red) coexpress the rod photoreceptor marker, Rhodopsin (green), indicating the generation of rod photoreceptor cells. (C' and C') High-power view of Recoverin and Rhodopsin immunostaining. (D) In differentiation medium containing only bFGF+RA, most differentiated photoreceptors (Recoverin, green) express a marker of cone photoreceptors, Opsin (red). (E-H) Generation of Recoverin-positive photoreceptors (green) with various differentiation media: bFGF+DHA (FD) (E), bFGF+DHA+RA (FDR) (F), bFGF+DHA+DAPT (FDD) (G), bFGF+DHA+DAPT+RA (FDDR) (H). (I) Percentage of Recoverin-positive photoreceptors generated using four differentiation media formulations. Data is shown as mean \pm SEM $\left({ }^{*} P<0.05\right)$. Blue, DAPI. 
experiments).

To further define the requirement of these added factors for photoreceptor cell differentiation, we designed four groups: $\mathrm{bFGF}+\mathrm{DHA}(\mathrm{FD}) ; \mathrm{bFGF}+\mathrm{DHA}+\mathrm{DAPT}$ (FDD); bFGF+DHA+RA (FDR); bFGF+DHA+DAPT + RA (FDDR). bFGF and DHA only induced $6.95 \% \pm$ $0.69 \%$ of cells (in total 1473 cells examined in three independent experiments) to express Recoverin (Figure 3E and 3I), while the addition of RA or DAPT significantly promoted the differentiation of photoreceptors, $30.73 \%$ $\pm 6.2 \%$ (in total 9937 cells examined in six independent experiments) or $24.6 \% \pm 7.6 \%$ (in total 5124 cells examined in four independent experiments), respectively (Figure 3F-3G and 3I). The combination of both RA and DAPT further significantly increased the production of photoreceptors (Figure 3H-3I). We also found that $94 \%$ $\pm 2.2 \%$ of Recoverin-positive cells are also Rhodopsin positive (indicative of rod photoreceptor cells) in the $\mathrm{bFGF}+\mathrm{RA}+\mathrm{DAPT}-\mathrm{containing} \mathrm{medium} \mathrm{(Figure} \mathrm{3C).} \mathrm{In}$ contrast, in the bFGF+RA-containing medium, $89 \% \pm$ $3.2 \%$ of Recoverin-positive cells express the marker Op$\sin$ (red/green), indicative of cone photoreceptors (Figure 3D). These results indicate that rod and cone photoreceptors can be preferentially generated from retinal stem cells under different culture conditions.

Survival and incorporation of retinal stem cell-derived rod photoreceptor cells after transplantation into the rd7 mouse

Previous results have shown that mouse photoreceptor precursor cells and human ES cell-derived photoreceptor cells incorporate effectively into adult retina when transplanted into the subretinal space [38]. The retinal degeneration $7(r d 7)$ mouse model is a naturally occurring model of enhanced S-cone syndrome, a disorder that makes those affected sensitive to blue light and susceptible to developing night blindness at an early age. In humans, the corresponding allelic disorder is caused by inactivation of a photoreceptor-specific nuclear hormone receptor, NR2E3 [39, 40]. Previous studies have demonstrated that transplantation is successful only when postmitotic yet not terminally differentiated photoreceptors are injected, but not proliferating progenitor cells [1]. To test whether differentiated photoreceptor cells derived from retinal stem cells can integrate into the retina, we induced differentiation of retinal stem cells in the $\mathrm{bFGF}+\mathrm{DHA}+\mathrm{RA}+\mathrm{DAPT}$-containing differentiation medium for 4 days, and transplanted $0.5-1.0 \times 10^{5}$ cells into the subretinal space of $r d 7$ pups at 3 days of age. After 4 to 5 weeks, many GFP-labeled cells left the subretinal space and migrated into the ONL layer (Figure 4A). Integrated cells had the morphological appearance of mature rod photoreceptors and their identity was confirmed with four criteria. First, most ( $>94 \%$ ) were correctly oriented within the ONL, spanned the whole ONL, and had morphological features typical of mature photoreceptors: outer segments, inner segment and synapse structure (Figure 4B and Supplementary information, Figure S4). Second, Rhodopsin staining showed that many cells $(62.5 \% \pm$ $6.5 \%$, based on the analysis of 320 GFP-positive cells, $n$ $=4$ eyes) that migrated into the ONL express Rhodopsin, a critical element of the phototransduction cascade in mature photoreceptors (Figure 4C-4E and Supplementary information, Figure S4). Consistent with the nuclei of the host photoreceptor cells, the grafted Rhodopsin-positive cells exhibit similarly condensed nuclei (Figure 4D-4E). Third, integrated cells expressed the ribbon synapse protein Bassoon (Figure 4F-4I). Finally, integrated cells assemble synaptic contact with rod bipolar cells, identified by immunostaining for Protein Kinase C (PKC) (Figure 4J-4L). Together, these findings confirm the identity of the integrated cells as rod photoreceptors that correctly express essential proteins for phototransduction.

Transplanted photoreceptors from retinal stem cells provide functional and structural retinal rescue

The FVB/NJ $r d 1$ mutant mouse harbors a mutation of the $P D E 6 b$ gene and is a model for rapidly progressive photoreceptor degeneration. In these animals, retinal function is severely impaired by $2-3$ weeks of age due to rapidly progressive retinal ONL degeneration that results in reduction to a single cell layer of photoreceptors and eventually progresses to zero photoreceptors. In humans, mutations in the rod photoreceptor PDE6B gene are found in patients with autosomal recessive retinitis pigmentosa (RP) $[41,42]$. To test whether the photoreceptors derived from retinal stem cells can rescue lost vision in the disease model, $1-1.5 \times 10^{5}$ cells (of which $56 \%-73 \%$ were rod photoreceptors) were grafted into subretinal space of 403 -day-old FVB/NJ pups $(0.5 \mu \mathrm{l} /$ eye). One eye was injected with cells, while the other nontransplanted eye served as a control. Retinal function and structure was studied at 4-5 weeks post-transplantation, after the host photoreceptors had undergone extensive degeneration. The transplanted photoreceptors, large and expanded clusters of subretinal $\mathrm{GFP}^{+}$cells, could be observed by a fluorescence microscope in the enucleated eye (Figure 5A). Histological analysis showed that most of GFP-positive cells (>90\%) resided adjacent to or within the outermost side of the inner nuclear layer and a few cells $(5 \% \pm 2.5 \%, n=4$ eyes $)$ migrated into IPL (Figure 5B and Supplementary information, Figure S5A). Grafts were often dispersed over a large area (Figure 5B-5D and Supplementary information, Figure S5A). 


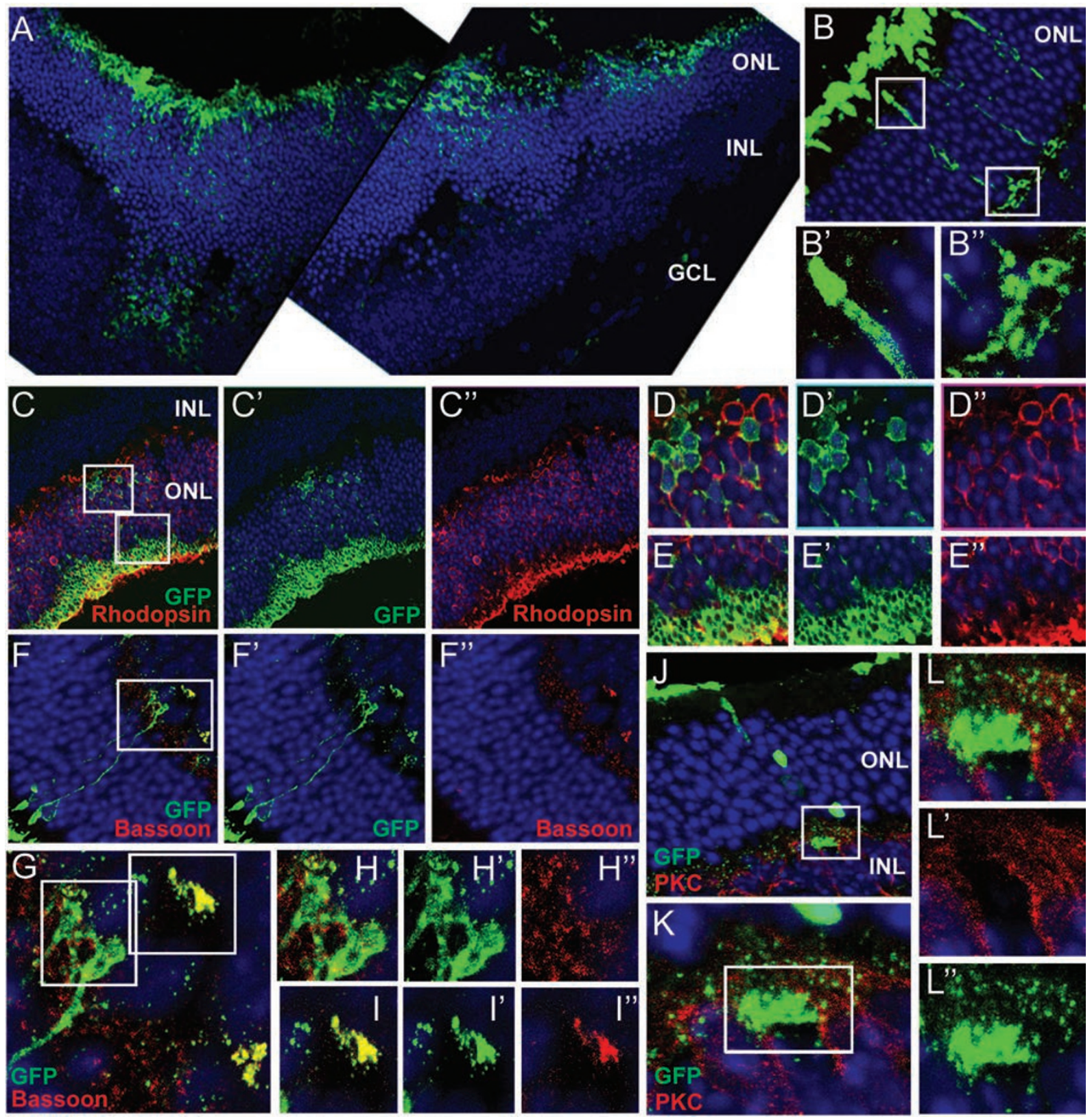

Figure 4 Survival and incorporation of retinal stem cell-derived rod photoreceptor cells after transplantation into rd7 mouse. (A) GFP-expressing differentiated photoreceptors (green) migrate into the ONL from the subretinal space. At the region into which many GFP ${ }^{+}$cells integrate, the ONL becomes significantly thicker compared with other regions. (B-B") Integrated $\mathrm{GFP}^{+}$cells have typical photoreceptor morphology with formation of outer segments and synapses, similar to photoreceptors in host retina. (B' and B') are high-power views of the boxed region in B. (C-E) Some integrated GFP ${ }^{+}$cells express a functional marker of rod photoreceptors, Rhodopsin (red). A high-power view of boxed regions of $\mathbf{C}$ show GFP ${ }^{+}$and Rhodopsin ${ }^{+}$ cell bodies (D-D") and outer segments (E-E'). (F-I) Integrated photoreceptors express the pre-synaptic protein Bassoon (red). (G) shows a high-power view of the boxed region in (F), and (H-H') and (I-I") show high-power views of the boxed regions in (G). (J-L) Transplanted photoreceptors form synapse connectivity with host bipolar cells (red, PKC). (K) A magnified view of the boxed region of (J). (L-L") A high-power view of the boxed region in (K). Blue, DAPI.

In some cases, the transplanted cells formed a new layer of cells adjacent to the degenerated host ONL in the sub- retinal space and expressed Rhodopsin (Figure 5C-5D).

The function of the transplanted cells was tested with 

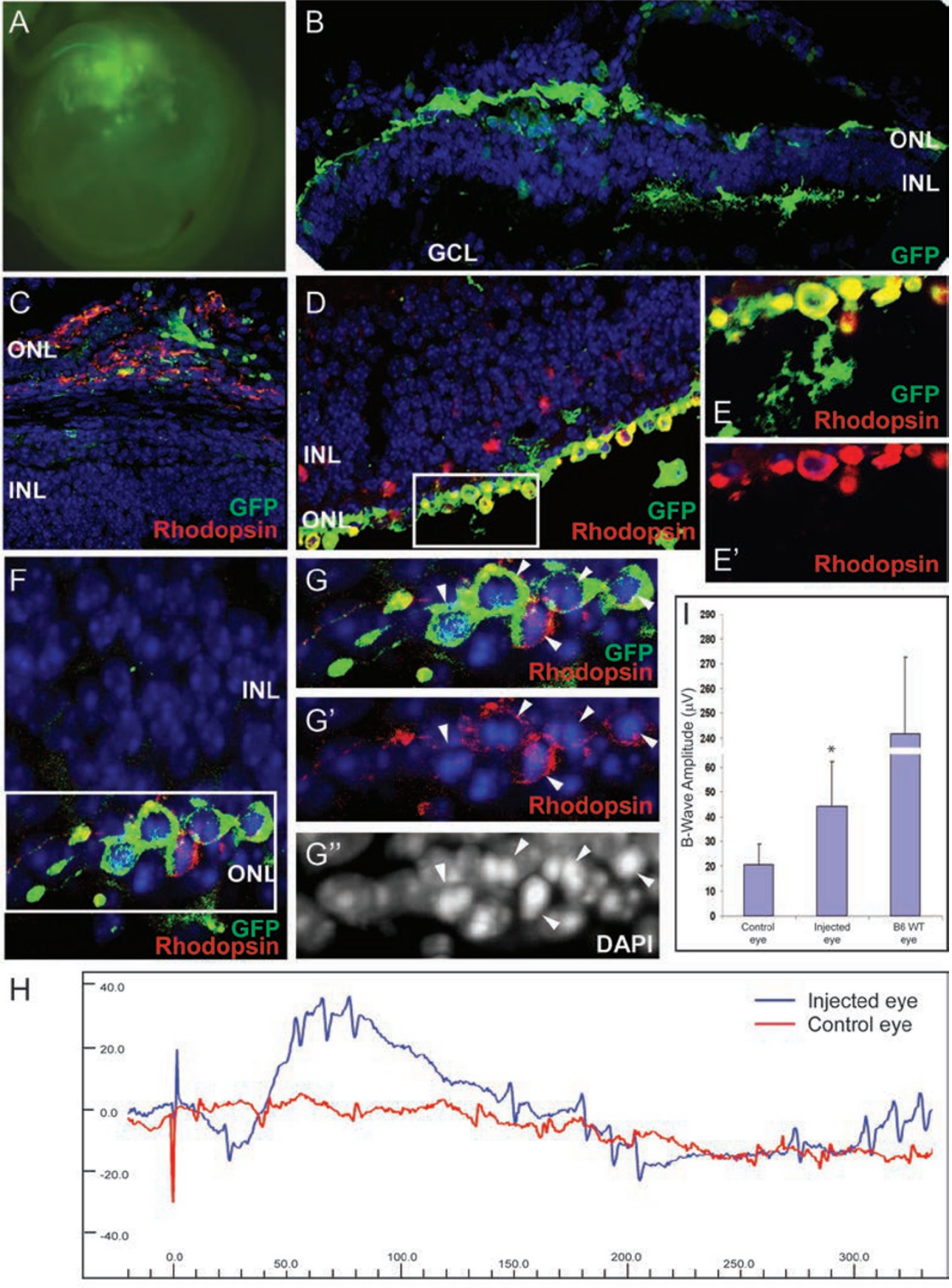

Milliseconds

Figure 5 Transplanted photoreceptors from retinal stem cells provide functional and structural retinal rescue in retinitis pigmentosa disease model. (A) Fluorescence microscope image of eye shows large clusters of GFP ${ }^{+}$cells $4-5$ weeks after FVB/ NJ pups are transplanted with photoreceptors derived from retinal stem cells. (B) Histological immunostaining of transplanted retina shows that many transplanted $\mathrm{GFP}^{+}$cells leave the subretinal space and integrate into the remaining ONL, the OPL and INL and a few cells migrate into IPL layer, while host photoreceptors are degenerated. (C) In some cases, transplanted cells form a new layer between INL and pigmented layer and express rod photoreceptor marker, Rhodopsin. (D-G) Integrated GFP ${ }^{+}$cells express Rhodopsin and form condensed nuclei (arrowheads), similar to normal rod photoreceptors. (E-E' and G-G") are high-power images of the boxed regions in D and F. (H) A representative electroretinograph (ERG) from one mouse. The uninjected control eye (red) has no response to light stimulus, however, the transplanted eye from the same animal has a clear response to a flash of light. (I) Transplanted eyes exhibit significantly increased B-wave amplitudes following light flash compared with control eyes, though not reaching the amplitude exhibited by normal B6 wild-type mouse eyes. Data is shown as mean \pm SEM ( $\left.{ }^{*} P<0.01\right)$. Blue, DAPI. 
three different methods. First, within well-defined grafts, $72 \% \pm 8.7 \%$ of cells ( $n=5$ eyes) expressed the functional protein Rhodopsin with the typical condensed nucleus
(Figure 5D-5G). Second, Synaptophysin staining showed that some grafted cells formed axons, which are required for communication with downstream target cells (Sup-
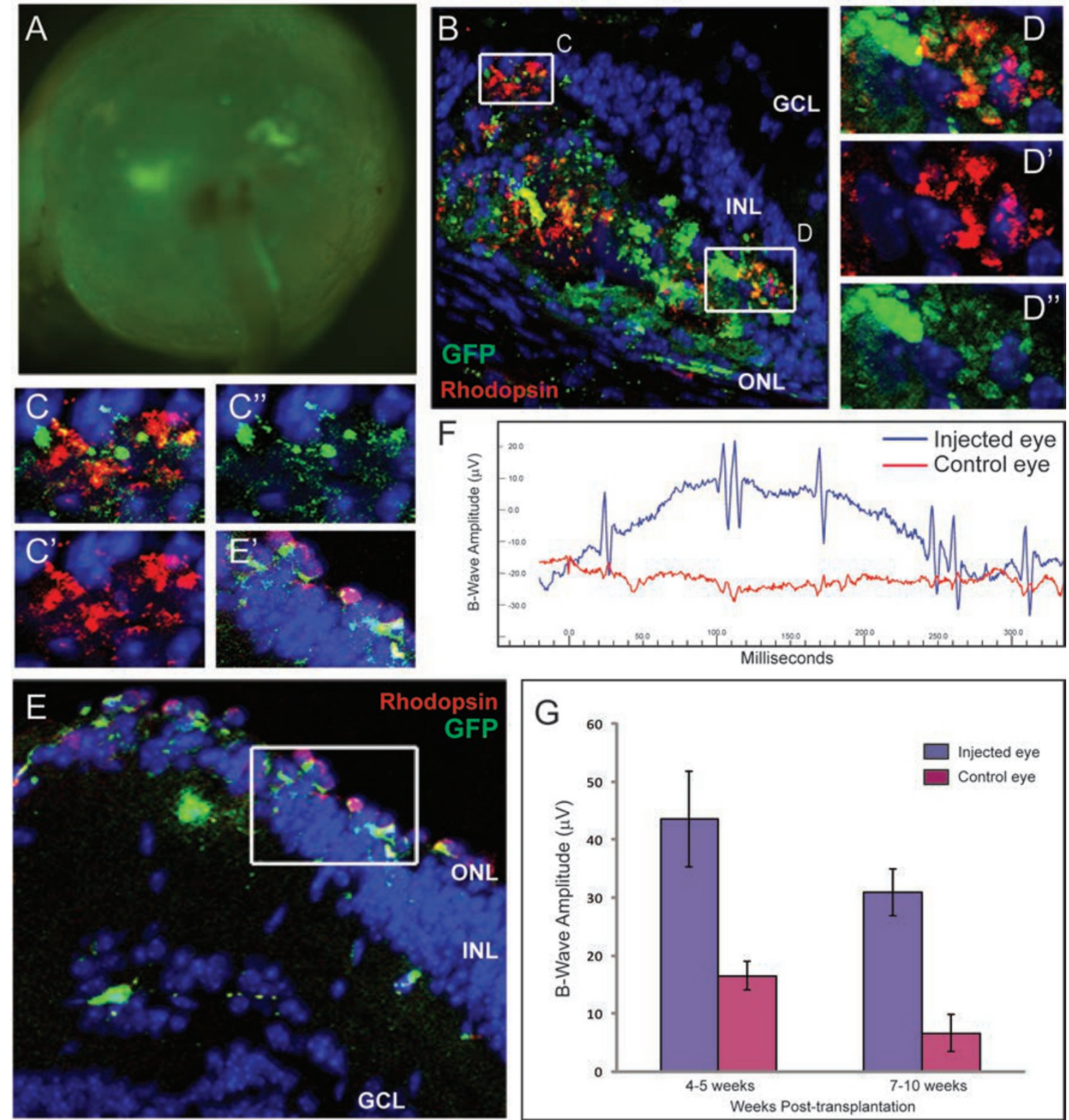

Figure 6 Transplanted photoreceptors from retinal stem cells remain and maintain long-term functions in the retinitis pigmentosa disease model. Six mice that were measured 4 weeks after transplantation and displayed a positive response to light flash were kept alive, and subjected to ERG and histological analysis again at 7-10 weeks post-transplantation. (A) Fluorescence microscope image of a transplanted eye, showing that clusters of $\mathrm{GFP}^{+}$cells remain in the retina 10 weeks after transplantation. (B-E) GFP' cells survive long-term and continue to express Rhodopsin (red). (C-C" and D-D") are the high-power views of the boxed regions in (B), (E') is a high-power view of the boxed region in (E). (B-D) are sections of the same eye, (E) demonstrates the same findings in a different injected eye. (F) A representative ERG from one mouse at 7 weeks posttransplantation. The control non-transplanted eye (red) has no response to light stimulus, however, the transplanted eye from the same animal has a clear response to a flash of light 7 weeks after transplantation. Of the six mice tested, three continued to display clear responses to light in the transplanted eye at the extended time point. (G) B-wave amplitudes of three mice following light flash at the two different time points. Data is shown as mean \pm SEM. Blue, DAPI. 
plementary information, Figure S5). Finally, the mice were analyzed for restoration of visual responses with electroretinogram (ERG) analysis 4-5 weeks after transplantation. The animals were dark-adapted overnight, and light flashes of increasing intensity were presented. The uninjected eye of FVB/NJ mice had essentially no light response as evidenced by a flat ERG (Figure $5 \mathrm{H}$ and Supplementary information, Figure S6A). However, the eye that received the transplanted cells had a clear response to a flash of light (Figure 5H and Supplementary information, Figure S6). Nine animals had some degree of ERG B-wave response in the injected eye with an average B-wave amplitude of $44.16 \pm 18.1 \mu \mathrm{V}(n=9, P<$ $0.01)$ compared with control eye amplitude of $20.81 \pm 8.0$ $\mu \mathrm{V}$. The B-wave amplitude of wild-type B6 mice under similar excitation conditions was $242 \pm 31.02 \mu \mathrm{V}, n=$ 4 eyes (Figure 5I). In injected eyes where no cells were found in the subretinal space or inside the retina at the time of analysis, we also did not see any increase in Bwave amplitude (18.6 $\pm 7.8 \mu \mathrm{V} ; n=10$ eyes), compared with uninjected eyes (data not shown).

To test whether transplanted cells can be maintained for a long time in the degenerated retina, six mice that were measured 4-5 weeks after transplantation and displayed positive response to light flash were kept alive and analyzed again 7-10 weeks after transplantation. Clusters of subretinal $\mathrm{GFP}^{+}$cells could still be observed by a fluorescence microscope in the enucleated eyes (Figure 6A). Furthermore, long-term surviving GFPpositive cells still expressed Rhodopsin (Figure 6B-6E). ERG measurement showed that three mice had a clear response to the light flash (Figure 6F-6G and Supplementary information, Figure S7). The B-wave amplitudes of three mice following light flash at 4-5 weeks and 7-10 weeks post-transplantation show that the eyes that received the transplanted cells had increased light response at both time points (Figure 6G). Both number of GFP-positive cells and ERG response were reduced in eyes analyzed at later time points compared with eyes analyzed at week 4 , indicating that the grafted cells may be lost over time.

\section{Discussion}

In this study, we have successfully cultured retinal stem cells isolated from the adult mouse neural retina that are capable of generating all major cell types of the neural retina in vitro. Most intriguingly, this population of cells is capable of differentiating into photoreceptor cells and restoring light response of photoreceptordegenerated $r d l$ mutant mice in vivo, demonstrating the therapeutic potential of using retinal stem cells isolated from adult retinas for treating retinal degenerative diseases.

The isolated cells clearly display the defining features of retinal stem cells: they possess high and stable proliferation ability in vitro over long-term culture; they highly express markers of neural stem cells and early embryonic retinal progenitor cells, including Sox2, Pax6, Nestin, A2B5, Lhx2, Chx10, Otx2, and Six3; they can differentiate into seven major types of mature retinal cells; differentiated cells generated from these retinal stem cells are capable of integrating into mouse retina and restoring a degree of lost vision after injection into diseased retina. In the adult mammalian retina, ciliary body epithelia cells and Müller glia cells have been shown to possess certain features of retinal stem cells [12, 14, 24]. Furthermore, amacrine cells and horizontal cells in the adult retina have been shown to reenter the cell cycle and give rise to retinoblastoma [43]. As we have carefully excluded ciliary body from our culture, the cell lines that we generated could not arise from ciliary body epithelium. In our efforts to characterize the origin of the retinal stem cells that we isolated from the adult retina, we obtained a GFAP-GFP strain of transgenic mice [44], which expresses GFP in Müller cells, and an Lgr5-GFP strain [45], which expresses GFP in amacrine cells. We sorted GFP-positive cells from dissected retinas from these two lines and cultured them using the same protocol for establishing retinal stem cells. Most isolated Lgr5-GFP-positive cells died, while some GFAP-GFPpositive cells survived and exhibited typical Müller cell morphology in culture. However, no cell lines could be generated after several attempts (Supplementary information, Figure S8). Though we cannot rule out the possibility that establishing retinal stem cell lines from these cell population requires support of other cells or extracellular components in the adult retina that are deprived during the sorting procedure, our failed attempts to culture Müller cells and amacrine cells and the low efficiency at which we have established retinal stem cell lines suggest that there might be a unique population of resident retinal stem cells in the adult retina or cultured retinal stem cells are reprogrammed from a rare subtype of mature retinal cells in culture. As cultured retinal stem cell lines express variable levels of GS and GFAP, the markers for Müller cells, it remains formally possible that some Müller cells are reverted back to the progenitor state in the presence of FGF and EGF. One gene expression study has shown that Müller cells are more similar to retinal progenitors than other retinal cell types [46].

Stem cell self-renewal and differentiation requires specific microenvironments, or niches [47]. In this study, we found that long-term maintenance of retinal stem 
cells requires both bFGF and EGF, similar to cultured neural stem cells. bFGF is required for efficient differentiation into retinal ganglion cells. In bFGF-supplemented culture medium, Müller cells and bipolar cells can also be generated. The Notch ligand JAG1 promotes amacrine cell differentiation, while the combination of bFGF, NGF and IGF-1 is required for the generation of horizontal cells. To search for the ideal protocol to induce our cultured retinal stem cells in order to differentiate into photoreceptor cells, we tested different combination of growth factors and small molecules, and found that the combination of bFGF, RA, DHA and DAPT dramatically promotes the differentiation of rod photoreceptors. These findings are consistent with previous in vivo studies [36, $37,48-50]$, raising an interesting possibility that cultured retinal stem cells could be an effective system for studying molecular mechanisms underlying lineage differentiation in vitro.

To test whether retinal stem cells can be used in future clinical applications, we transplanted retinal stem cells into two photoreceptor degeneration mouse models. First, differentiated retinal stem cells were transplanted into subretinal space of $r d 7$ mice, which is a model of enhanced S-cone syndrome in which mice exhibit slow rod photoreceptor degeneration [51]. The injected cells showed prominent integration into the ONL with typical photoreceptor morphology, spanned the entire ONL layer, expressed Rhodopsin, and formed synapse communication with host bipolar cells. Second, we transplanted differentiated retinal stem cells into subretinal space of $r d 1$ mutant mice, which is a RP model in which mice exhibit rapid photoreceptor degeneration [52]. Surprisingly, the engrafted cells integrated, replaced lost photoreceptors, and rescued some lost visual function as determined by positive response to ERG testing, even up to 10 weeks after transplantation. These transplantation experiments demonstrated that these retinal stem cells can be used for cell replacement of degenerated photoreceptors in the mouse.

Retinal degeneration represents one of the most prevalent health problems among the aged population and suitable cellular sources for cell replacement therapy are being intensely investigated. The limited sources of photoreceptor precursors from developing retina preclude its clinical application and oncogenic properties of ES cells and iPS cells bring serious safety concerns when using them on human patients [1, 8-11]. Isolation of multipotent stem cells from the adult human retina capable of expansion in vitro and highly efficient differentiation into mature retina cells remains one of the viable strategies toward treating patients suffering from retinal degeneration. Due to the advance of cornea trans- plantation therapy for cornea diseases, eye banking has become a common practice in many countries. The large collections of eye donors in eye banks provide a precious tissue source for generating retinal stem cell lines, and make it possible to establish a collection of human retinal stem cell lines with various HLA-haplotypes and genotypes to meet the needs of retina research and clinical applications. In the future, it will be of great interest to culture similar retinal stem cell lines from the cadaveric human retina and investigate their potential in generating functional photoreceptors for restoring lost vision in RP. In the case of AMD patients wherein retinal degeneration and loss of vision is caused by dysfunctional RPE cells, cotransplantation of photoreceptor cells with healthy RPE cells, or combining photoreceptor transplantation with gene therapy in the defective RPE, will likely be necessary to cure the disease.

\section{Materials and Methods}

\section{Eye dissection and retinal cell culture}

Eyes were collected from 4-8-week old CD-1 and B6 mice. The eyes were dissected and neuroretina was gently removed using jeweler's forceps, without disrupting the underlying retinal pigmented epithelium. The ciliary body and posterior retinal tissue surrounding the optic nerve head were excluded from the dissection. The retina was dissociated into small pieces with a pipette, and enzymatically digested with $10 \mathrm{mg} / \mathrm{ml}$ dispase for $10 \mathrm{~min}$. To obtain single cells, the digested retina tissue was transferred into $15 \mathrm{ml}$ centrifuge tubes and briefly centrifuged, allowing clumps to settle and single cells to remain in the supernatant. The supernatant was gently transferred into another tube without the disturbance of pelleted tissue and centrifuged for 4 min at $1300 \mathrm{rpm}$, and then resuspended in culture medium for retinal stem cells (RCM), similar to NDCM medium [53]. The remaining pelleted tissue was subjected to another round of dispase digestion for 8-10 min. This process was repeated three times. Finally, the remaining undigested tissue was incubated with $0.15 \%$ trypsin in $0.03 \%$ EDTA and $3 \mu \mathrm{l}$ DNase for another 8-10 min. The digestion was neutralized with 10\% FBS-containing DMEM/F12 medium. Single cells from each digestion were pooled and plated in RCM with $10 \%$ fetal bovine serum (FBS, Hyclone) (two wells of 24-well plate per eye). RCM: DMEM/F12 (1:1) with the following complements: InsulinTransferrin-Selenium-A Supplement (Invitrogen), $1.0 \mathrm{~g} / 1$ BSA (MP Biomedical), $1.0 \mathrm{~g} / \mathrm{l}$ glucose (Sigma), $1.0 \mathrm{~g} / 1$ lactose (Sigma), 0.045 $\mathrm{g} / 1$ proline (Sigma), $11.25 \mu \mathrm{g} / \mathrm{ml}$ linoleic acid (Sigma), $5 \mathrm{mM}$ glutamine (Invitrogen), $2 \mathrm{mM}$ nicotinamide (Sigma).

After $48 \mathrm{~h}$, the medium and unattached cells were gently aspirated and medium was completely replaced with fresh medium. After 4-6 days, attached cells began to proliferate, and culture medium was replaced with serum-free RCM supplemented with $5 \%$ Knockout Serum Replacement (Invitrogen). Every 2 days, 2/3 medium was replaced by fresh medium. In the 3-4 weeks of primary culture, very few spindle-shape cells were observed, but these cells expanded and formed colonies in the following 1-2 weeks. After the formation of this type of colony, Accutase (Sigma) was used to 
digest these cells and they were further passaged and expanded.

\section{$R N A$ isolation and $q R T-P C R$ analysis}

Total RNA was isolated from cells in culture using Trizol (Invitrogen) according to manufacturer's instructions. cDNA was generated using Superscript First-strand Synthesis Kit (Invitrogen). Reactions containing 2.0 $\mu \mathrm{l}$ cDNA were prepared in Sybr green master mix (Applied Biosystems) and subjected to quantitative real-time PCR analysis using ABI 7500 thermocycler. Each reaction was repeated in triplicate and the experiments were repeated at least twice to confirm reproducibility. Values were obtained for the threshold cycle $(\mathrm{Ct})$ for each gene and data were analyzed using the standard curve method. Values were normalized to the expression of Gapdh and the log of average relative expression \pm the SEM was reported. PCR primer sequences are reported in Supplementary information, Table S3.

\section{Differentiation into retinal cell subtypes}

Retinal stem cells cultured in vitro from passages 5 to 24 were digested into single cells with Accutase. A total of $1 \times 10^{5}$ cells/ well were seeded in 24-well culture plates on glass coverslips precoated with $0.015 \mathrm{mg} / \mathrm{ml}$ poly-L-ornithine (Sigma) and $20 \mu \mathrm{g} / \mathrm{ml}$ laminin (Invitrogen) in DMEM/F12 (1:1) (Invitrogen), B27 (1:50, Invitrogen), $2 \mathrm{mM}$ glutamine (NCM medium), with or without bFGF (10 ng/ml). After 2 days, cells were switched to NCM plus N2 (1:100, Invitrogen) for four more days to induce cell differentiation and maturation.

Amacrine cell differentiation: $1 \times 10^{5}$ cells/well were seeded in 24-well culture plates on glass coverslips pre-coated with poly-Lornithine and laminin in NCM medium plus 40 nM JAG1 (188-204, AnaSpec, Inc.) for 6 days.

Horizontal cell differentiation: $1 \times 10^{5}$ cells/well were seeded in 24-well culture plates on glass coverslips pre-coated with poly-Lornithine and laminin in DMEM/F12, B27, $10 \mathrm{ng} / \mathrm{ml}$ bFGF, $10 \mathrm{ng} /$ $\mathrm{ml}$ nerve growth factor (NGF) and $10 \mathrm{ng} / \mathrm{ml}$ insulin-like growth factor 1 (IGF-1) for 8 days.

Photoreceptor cell differentiation: $2 \times 10^{5}$ cells/well were seeded in 24-well culture plates on coverslips pre-coated with poly-L-ornithine and laminin in DMEM/F12 or Neurobasal (Invitrogen) medium containing N2, B27, and supplemented with the different combinations of $10 \mathrm{ng} / \mathrm{ml} \mathrm{bFGF}, 50 \mathrm{nM}$ DHA (Docosahexaenoic acid, Sigma), $2 \mu$ M RA (Retinoic acid, Sigma), 10 $\mu \mathrm{M}$ DAPT ( $\gamma$-secretase inhibitor, Sigma). Five groups of culture conditions were tested: FGF (bFGF), FD (bFGF+DHA), FDR $(\mathrm{bFGF}+\mathrm{DHA}+\mathrm{RA}), \mathrm{FDD}(\mathrm{bFGF}+\mathrm{DHA}+\mathrm{DAPT})$, and FDDR $(\mathrm{bFGF}+\mathrm{DHA}+\mathrm{DAPT}+\mathrm{RA})$. For photoreceptor cell maturation, differentiation medium was changed to maturation medium 4 days later: DMEM/F12 or Neurobasal, B27, and supplemented with $10 \mathrm{ng} / \mathrm{ml} \mathrm{BDNF}, 10 \mathrm{ng} / \mathrm{ml} \mathrm{IGF-1,} \mathrm{and} 10 \mathrm{ng}$ NGF for another 4-6 days.

\section{Immunocytochemical staining (ICC)}

Standard protocols were used for ICC. In general, cells were fixed with $4 \%$ formaldehyde (Sigma) in PBS for 10 min at room temperature. After blocking with $10 \%$ goat or donkey serum, the cells were stained for $1 \mathrm{~h}$ at room temperature with one of the following primary antibodies: mouse anti-Nestin (1:400), rabbit antiRecoverin (1:500), mouse A2B5 (1:400), mouse anti-Rhodopsin (1:300), mouse anti-Crx (1:400), chicken anti-Opsin (red/green;
1:500), rabbit anti-Opsin (red/green; 1:300), mouse anti-Neuronal nuclei $(\mathrm{NeuN} ; 1: 100)$, mouse anti-Growth Associated Protein-43 (GAP-43; 1:500), rabbit anti-Sox2 (1:1 000), goat anti-Vimentin (1:300) (all from Chemicon International); mouse anti-Syntaxin (HPC-1; 1:400), rabbit anti-Calbindin (1:500), rabbit anti-Glutamine Synthetase (GS, 1:2 500), rabbit anti-Glial Fibrillary Acidic Protein (GFAP, 1:1 000), rabbit anti-Protein Kinase C (PKC, 1:2 500) (all from Sigma); mouse anti-Isl1(supernatant, 1:10), mouse anti-rat Radial glial cell marker (RC2; 1:5), mouse anti-Neurofilament H (1:10), mouse anti-Pax6 (1:10) (all from Developmental Studies Hybridoma Bank); mouse anti-Bassoon (1:300; StressGen Biotechnologies), rabbit anti-Pax2 (1:400; Invitrogen), mouse antiGFAP (DAKO; 1:2 500), mouse anti- $\beta$-tubulin III (1: 2 000; Promega), rabbit anti- $\beta$-tubulin III (1:1 200; COVANCE), mouse antiMicrotubule Associated Protein 2 (MAP2) (1:200; COVANCE), rabbit anti-SynapsinI (Abcam), mouse anti-Synaptophysin (Millipore), and chicken anti-GFP (Invitrogen). The cells were then rinsed three times with PBS and incubated for $1 \mathrm{~h}$ at room temperature with the corresponding goat secondary antibody. Negative controls for each fluorophore-conjugated secondary antibody, carried out without the addition of primary antibody, were included in order to evaluate nonspecific binding of secondary antibodies. After immunostaining, cells were counterstained with DAPI nuclear stain. For BrdU staining, before BrdU antibody (Megabase Research Products) incubation, retinal cells were incubated in $1 \mathrm{M}$ $\mathrm{HCl}$ for $0.5 \mathrm{~h}, 0.1 \mathrm{M} \mathrm{Na}$-Borate for $20 \mathrm{~min}$ at room temperature and washed $3 \times 10 \mathrm{~min}$ in TBS.

\section{Lentivirus plasmid construction and infection}

pSico-GFP (Addgene) was used to lentivirally transduce mouse retinal stem cells. Lentiviruses was produced by cotransfecting 293 T cells with the construct and packaging plasmids pLP1 and pLP2. High-titer virus was added to culture medium of retinal stem cells at $40 \%$ confluency. After $4 \mathrm{~h}$, the culture medium was replaced by fresh culture medium.

Transplantation of differentiated photoreceptors from retinal stem cells into subretinal space of newborn $r d 7$ and FVB/NJ pups

All animal experiments were conducted according to the ARVO Statement for the Use of Animals in Ophthalmic and Vision Research and approved by the Institutional Committee for Animal Research at the Stowers Institute for Medical Research. GFP-labeled retinal stem cells were differentiated in bFGF+DHA + DAPT+RA medium for 4 days. The success of photoreceptor differentiation was confirmed by Crx immunostaining on Day 3 . Differentiated cells were dissociated into single cells, and resuspended in DMEM/F12 medium with B27 at a concentration of $1 \times$ $10^{5}$ cells per $\mu$ l. Postnatal day $3 r d 7$ or FVB pups were anesthetized on ice. The sclera was carefully punctured nasally $\sim 0.5$ to $1 \mathrm{~mm}$ close to ciliary margin with a 33 -gauge needle to produce a hole. The blunt needle tip carrying cells and dye was inserted through the sclera puncture, avoiding trauma to the lens. Subsequently, the needle shaft was aimed slightly nasally toward the desired injection location (close to optic nerve). A slight resistance to the movement of the needle indicated penetration of the retina and entrance into the subretinal matrix. A total of $0.2-0.5 \mu 1$ of cells (2 $\times 10^{5}$ cells $/ \mu \mathrm{l}$ ) were injected slowly over the course of $\sim 30 \mathrm{~s}$. After 4-10 weeks of transplantation, animals were sacrificed and the 
eyes were collected and fixed with 4\% paraformaldehyde. Twelve micrometers thick cryosections were made for further analysis by immunohistochemistry.

\section{Electroretinography}

For ERG analysis of FVB/NJ mice, one eye per pup was injected with cells while the other eye remained uninjected to serve as a control. Mice were dark-adapted overnight and anaesthetized with $2.5 \%$ Avertin. Pupils were dilated by topical application of tropicamide and phenylephrine $10 \mathrm{~min}$ before ERG recordings. Mice were placed on a heating pad and maintained at $37{ }^{\circ} \mathrm{C}$. A silver embedded thread electrode was placed across the apex of each cornea and held in place with an optically clear mini-contact lens and a drop of $2.5 \%$ methylcellulose. Stainless steel needle reference electrodes were placed subcutaneously into each cheek, and a stainless steel needle ground electrode was inserted subcutaneously into the base of the tail. Scotopic ERGs were recorded bilaterally using the Ocuscience HMsERG (Rolla, MO, USA). Responses to six different full-field flash intensities were collected from each mouse. ERG data was analyzed using ERGVIEW (Ocuscience) and signals were subjected to $60 \mathrm{~Hz}$ notch filtering.

\section{Acknowledgments}

We would like to thank the Xie laboratory members for stimulating discussions, the Laboratory Animal Services Facility at SIMR for maintaining our mouse strains, and C Flournoy for administrative assistance. This work was supported by a fund from Stowers Institute for Medical research (T Xie).

\section{References}

1 MacLaren RE, Pearson RA, MacNeil A, et al. Retinal repair by transplantation of photoreceptor precursors. Nature 2006; 444:203-207.

2 Pearson RA, Barber AC, Rizzi M, et al. Restoration of vision after transplantation of photoreceptors. Nature 2012; 485:99103.

3 Ikeda H, Osakada F, Watanabe $\mathrm{K}$, et al. Generation of $\mathrm{Rx}+/$ Pax6+ neural retinal precursors from embryonic stem cells. Proc Natl Acad Sci USA 2005; 102:11331-11336.

4 Lamba DA, Karl MO, Ware CB, Reh TA. Efficient generation of retinal progenitor cells from human embryonic stem cells. Proc Natl Acad Sci USA 2006; 103:12769-12774.

5 Osakada F, Ikeda H, Mandai M, et al. Toward the generation of rod and cone photoreceptors from mouse, monkey and human embryonic stem cells. Nat Biotechnol 2008; 26:215-224.

6 Eiraku M, Takata N, Ishibashi H, et al. Self-organizing opticcup morphogenesis in three-dimensional culture. Nature 2011; 472:51-56.

7 Nakano T, Ando S, Takata N, et al. Self-formation of optic cups and storable stratified neural retina from human ESCs. Cell Stem Cell 2012; 10:771-785.

8 Lamba DA, Gust J, Reh TA. Transplantation of human embryonic stem cell-derived photoreceptors restores some visual function in Crx-deficient mice. Cell Stem Cell 2009; 4:73-79.

9 Lamba DA, McUsic A, Hirata RK, Wang PR, Russell D, Reh TA. Generation, purification and transplantation of photoreceptors derived from human induced pluripotent stem cells.
PloS One 2010; 5:e8763.

10 Tucker BA, Park IH, Qi SD, et al. Transplantation of adult mouse iPS cell-derived photoreceptor precursors restores retinal structure and function in degenerative mice. PloS One 2011; 6:e18992.

11 West EL, Gonzalez-Cordero A, Hippert C, et al. Defining the integration capacity of embryonic stem cell-derived photoreceptor precursors. Stem Cells 2012; 30:1424-1435.

12 Tropepe V, Coles BL, Chiasson BJ, et al. Retinal stem cells in the adult mammalian eye. Science 2000; 287:2032-2036.

13 Ahmad I, Tang L, Pham H. Identification of neural progenitors in the adult mammalian eye. Biochem Biophys Res Commun 2000; 270:517-521.

14 Coles BL, Angenieux B, Inoue T, et al. Facile isolation and the characterization of human retinal stem cells. Proc Natl Acad Sci USA 2004; 101:15772-15777.

15 MacNeil A, Pearson RA, MacLaren RE, Smith AJ, Sowden JC, Ali RR. Comparative analysis of progenitor cells isolated from the iris, pars plana, and ciliary body of the adult porcine eye. Stem Cells 2007; 25:2430-2438.

16 Cicero SA, Johnson D, Reyntjens S, et al. Cells previously identified as retinal stem cells are pigmented ciliary epithelial cells. Proc Natl Acad Sci USA 2009; 106:6685-6690.

17 Gualdoni S, Baron M, Lakowski J, et al. Adult ciliary epithelial cells, previously identified as retinal stem cells with potential for retinal repair, fail to differentiate into new rod photoreceptors. Stem Cells 2010; 28:1048-1059.

18 Kriegstein A, Alvarez-Buylla A. The glial nature of embryonic and adult neural stem cells. Annu Rev Neurosci 2009; 32:149-184.

19 Bernardos RL, Barthel LK, Meyers JR, Raymond PA. Latestage neuronal progenitors in the retina are radial Müller glia that function as retinal stem cells. J Neurosci 2007; 27:70287040.

20 Yurco P, Cameron DA. Responses of Müller glia to retinal injury in adult zebrafish. Vision Res 2005; 45:991-1002.

21 Ooto S, Akagi T, Kageyama R, et al. Potential for neural regeneration after neurotoxic injury in the adult mammalian retina. Proc Natl Acad Sci USA 2004; 101:13654-13659.

22 Dyer MA, Cepko CL. Control of Müller glial cell proliferation and activation following retinal injury. Nat Neurosci 2000; 3:873-880.

23 Karl MO, Hayes S, Nelson BR, Tan K, Buckingham B, Reh TA. Stimulation of neural regeneration in the mouse retina. Proc Natl Acad Sci USA 2008; 105:19508-19513.

24 Das AV, Mallya KB, Zhao X, et al. Neural stem cell properties of Müller glia in the mammalian retina: regulation by Notch and Wnt signaling. Dev Biol 2006; 299:283-302.

25 Chacko DM, Rogers JA, Turner JE, Ahmad I. Survival and differentiation of cultured retinal progenitors transplanted in the subretinal space of the rat. Biochem Biophys Res Commun 2000; 268:842-846.

26 Yang P, Seiler MJ, Aramant RB, Whittemore SR. In vitro isolation and expansion of human retinal progenitor cells. Exp Neurol 2002; 177:326-331.

27 Klassen H, Kiilgaard JF, Warfvinge K, et al. Photoreceptor differentiation following transplantation of allogeneic retinal progenitor cells to the dystrophic rhodopsin pro347leu transgenic pig. Stem Cells Int 2012; 2012:939801. 
28 Klassen HJ, Ng TF, Kurimoto Y, et al. Multipotent retinal progenitors express developmental markers, differentiate into retinal neurons, and preserve light-mediated behavior. Invest Ophthalmol Vis Sci 2004; 45:4167-4173.

29 Taranova OV, Magness ST, Fagan BM, et al. SOX2 is a dosedependent regulator of retinal neural progenitor competence. Genes Dev 2006; 20:1187-1202.

30 Marquardt T, Ashery-Padan R, Andrejewski N, Scardigli R, Guillemot F, Gruss P. Pax6 is required for the multipotent state of retinal progenitor cells. Cells 2001; 105:43-55.

31 Nunes MC, Roy NS, Keyoung HM, et al. Identification and isolation of multipotential neural progenitor cells from the subcortical white matter of the adult human brain. Nat Med 2003; 9:439-447.

32 Chow RL, Lang RA. Early eye development in vertebrates. Annu Rev Cell Dev Biol 2001; 17:255-296.

33 Merkle FT, Tramontin AD, García-Verdugo JM, AlvarezBuylla A. Radial glia give rise to adult neural stem cells in the subventricular zone. Proc Natl Acad Sci USA 2004; 101:17528-17532.

34 Stanke J, Moose HE, El-Hodiri HM, Fischer AJ. Comparative study of Pax2 expression in glial cells in the retina and optic nerve of birds and mammals. J Comp Neurol 2010; 518:23162333.

35 Bao Z-Z, Cepko CL. The expression and function of notch pathway genes in the developing rat eye. J Neurosci 1997; 17:1425-1434.

36 Hyatt GA, Schmitt EA, Fadool JM, Dowling JE. Retinoic acid alters photoreceptor development in vivo. Proc Natl Acad Sci USA 1996; 93:13298-13303.

37 Levine EM, Fuhrmann S, Reh TA. Soluble factors and the development of rod photoreceptors. Cell Mol Life Sci 2000; 57:224-234.

38 Lamba DA, Gust J, Reh TA. Transplantation of human embryonic stem cell-derived photoreceptors restores some visual function in crx-deficient mice. Cell Stem Cell 2009; 4:73-79.

39 Akhmedov NB, Piriev NI, Chang B, et al. A deletion in a photoreceptor-specific nuclear receptor mRNA causes retinal degeneration in the rd7 mouse. Proc Natl Acad Sci USA 2000; 97:5551-5556.

40 Haider NB, Naggert J, Nishina PM. Excess cone cell proliferation due to lack of a functional NR2E3 causes retinal dysplasia and degeneration in $\mathrm{rd} 7 / \mathrm{rd} 7$ mice. Hum Mol Genet
2001; 10:1619-1626.

41 Bowes C, Li T, Danciger M, Baxter LC, Applebury ML, Farber DB. Retinal degeneration in the rd mouse is caused by a defect in the [beta] subunit of rod cGMP-phosphodiesterase. Nature 1990; 347:677-680.

42 Farber DB, Park S, Yamashita C. Cyclic GMP-phosphodiesterase of rd retina: biosynthesis and content. Exp Eye Res 1988; 46:363-374.

43 Ajioka I, Martins RA, Bayazitov IT, et al. Differentiated horizontal interneurons clonally expand to form metastatic retinoblastoma in mice. Cell 2007; 131:378-390.

44 Zhuo L, Sun B, Zhang CL, Fine A, Chiu SY, Messing A. Live astrocytes visualized by green fluorescent protein in transgenic mice. Dev Biol 1997; 187:36-42.

45 Barker N, van Es JH, Kuipers J, et al. Identification of stem cells in small intestine and colon by marker gene Lgr5. $\mathrm{Na}$ ture 2007; 449:1003-1007.

46 Roesch K, Jadhav AP, Trimarchi JM, et al. The transcriptome of retinal Müller glial cells. J Comp Neurol 2008; 509:225238.

47 Xie T, Li L. Stem cells and their niche: an inseparable relationship. Development 2007; 134:2001-2006.

48 Altshuler D, Lo Turco JJ, Rush J, Cepko C. Taurine promotes the differentiation of a vertebrate retinal cell type in vitro. Development 1993; 119:1317-1328.

49 Jadhav AP, Cho SH, Cepko CL. Notch activity permits retinal cells to progress through multiple progenitor states and acquire a stem cell property. Proc Natl Acad Sci USA 2006; 103:18998-19003.

50 Jadhav AP, Mason HA, Cepko CL. Notch 1 inhibits photoreceptor production in the developing mammalian retina. Development 2006; 133:913-923.

51 Akhmedov NB, Piriev NI, Chang B, et al. A deletion in a photoreceptor-specific nuclear receptor mRNA causes retinal degeneration in the rd7 mouse. Proc Natl Acad Sci USA 2000; 97:5551-5556.

52 Bowes C, Li T, Danciger M, Baxter LC, Applebury ML, Farber DB. Retinal degeneration in the rd mouse is caused by a defect in the beta subunit of rod cGMP-phosphodiesterase. Nature 1990; 347:677-680.

53 Li T, Zheng J, Xie Y, et al. Transplantable neural progenitor populations derived from rhesus monkey embryonic stem cells. Stem Cells 2005; 23:1295-1303.

(Supplementary information is linked to the online version of the paper on the Cell Research website.) 